\title{
Incremental Improvement of the Evaluation Algorithm in the Concept Map Based Knowledge Assessment System
}

\author{
Alla Anohina, Marks Vilkelis, Romans Lukasenko
}

Riga Technical University, Department of Systems Theory and Design

Kalku street 1, Riga, Latvia, LV-1658

E-mail: alla.anohina@rtu.lv, markvilkel@inbox.lv, lrexpress@inbox.lv

\begin{abstract}
The paper is devoted to the knowledge assessment system that has been developed at the Department of Systems Theory and Design of Riga Technical University for the last four years. The system is based on concept maps that allow displaying the knowledge structure of a particular learner in the form of a graph. Teacher's created concept maps serve as a standard against which learner's concept maps are compared. However, it is not correct to compare teacher's and learners' concept maps by examining the exact equivalence of relationships in both maps, because people construct knowledge in different ways. Thus, an appropriate mechanism is needed for the flexible evaluation of learners' concept maps. The paper describes the algorithm implemented in the concept map based knowledge assessment system and its evolution through four prototypes of the system.
\end{abstract}

Keywords: knowledge assessment system, concept maps, evaluation algorithm

\section{Introduction}

Rapid development of information and communication technologies and availability of huge amount of electronic information resources has led to changes in the roles of the main actors of the educational process, namely, a teacher and a learner. Nowadays teachers should guide learners through the learning process by advising them and providing necessary stimuli while learners search information in different places, inter alia in e-learning environments (for example, [1,2]) and turn it into knowledge. Special methods are needed for the evaluation of learners' knowledge structures created in such conditions and one of them is concept maps that allow displaying the knowledge structure of a particular learner in the form of a graph.

The Department of Systems Theory and Design of the Faculty of Computer Science and Information Technology of Riga Technical University has been developing the concept map based knowledge assessment system since the year 2005. The system has twofold goals in the context of the integration of technology into the traditional educational process: 1) to promote learners' knowledge self-assessment, and 2) to support the teacher in the improvement of the learning course through systematic assessment of learners' knowledge and analysis of its results. The goals are reached by the use of concept maps as an assessment tool. Three prototypes of the system have been already implemented and the fourth one is under development at the moment [3]. The paper is a logical continuation of the description of the system's working principles presented in [4] by focusing on a different aspect of its functionality, namely, on the algorithm for the comparison of learner's and teacher's concept maps and its incremental improvement through system's prototypes.

The paper is organized as follows. Section 2 gives an overview of the system. Section 3 discusses related works concerning scoring systems of concept maps. Evolution of the algorithm for the comparison of learner's and teacher's concept maps is described in Section 4. Finally, conclusions are presented. 


\section{Overview of the system}

As it was mentioned in Introduction concept maps are used as an assessment tool in the developed knowledge assessment system. According to [5] they can foster the learning of well-integrated structural knowledge as opposed to the memorization of fragmentary, unintegrated facts and externalize the conceptual knowledge (both correct and erroneous) that learners hold in a knowledge domain. A concept map is a graph with labeled nodes corresponding to concepts in a problem domain and with arcs indicating relationships between pairs of concepts. Arcs can be directed or undirected and with or without linking phrases on them. A linking phrase specifies the kind of a relationship between concepts. Concept map based tasks can be divided in 1) "fill-in-the map" tasks, where the structure of a concept map is given to the learner and he/she must fill it using the provided set of concepts and/or linking phrases, and 2) "construct-a-map" tasks, where the learner must decide on the structure of the concept map by $\mathrm{him} /$ herself.

The developed concept map based knowledge assessment system is used in the following way. The teacher defines stages of knowledge assessment and creates concept maps for all of them by specifying relevant concepts and relationships among them in such a way that the concept map of each stage is nothing else then an extension of the previous one. Thus, the concept map of the last stage includes all concepts and relationships among them. Teacher's created concept maps serve as a standard against which the learners' concept maps are compared. During knowledge assessment the learner solves a concept map based task corresponding to the assessment stage. After the learner has submitted his/her solution, the system compares the concept maps of the learner and the teacher, calculates the score of the learner's result and generates feedback.

The system offers five concept map based tasks that are ranged from the easiest to the most difficult (Figure 1) [6]. Eight transitions between tasks are implemented allowing the learner to find a task most suitable for his/her knowledge level. Four transitions increase the degree of task difficulty. They are carried out after the analysis of the learner's solution if the learner has reached the teacher's specified number of points in the current assessment stage without reducing the degree of difficulty of the original task. So, this is a system's adaptive reaction to the learner's behavior. Other four transitions reduce the degree of task difficulty and they are carried out by the voluntary request from the learner during the solving of the task.

Thus, the system supports knowledge self-assessment as it makes the analysis and evaluation of learners' concept maps, as well as provides feedback about the learner's errors. It promotes systematic knowledge assessment because it allows the extension of the initially created concept map for other assessment stages. Moreover, statistical information about differences between learners' concept maps and teacher's concept map is collected providing opportunities for the teacher to improve the learning course [4].

The system is implemented as a Web-based three-tier client-server application $[4,7]$ consisting of the following architectural layers (Figure 2): 1) a data storage layer represented by Data Base Management System (DBMS); 2) an application logics layer composed of the application server and the server side code running on it; a special persistence and query framework is used to communicate with the DBMS; and 3) the representation layer or graphical user interface.

As it is shown in Figure 2 the concept map based knowledge assessment system can be divided into three logical domains: administrator, teacher and student. Each domain has its own goal, but they are strictly linked together. Functionality of each domain can be used by one of three user roles which names correspond to the names of the domains. An administrator is responsible for the administration and maintenance of the whole system using such functions as input, editing and deleting of data about users (teachers and students), courses and student groups. The teacher domain provides all necessary functions for the creation of concept maps and defining of their attributes, as well as for the viewing of learners' results. Functionality of the student domain includes all things related to the completion of the 
concept map based tasks by learners and providing of feedback after the completion of the task.

Increase of difficulty: adaptive reaction of the system

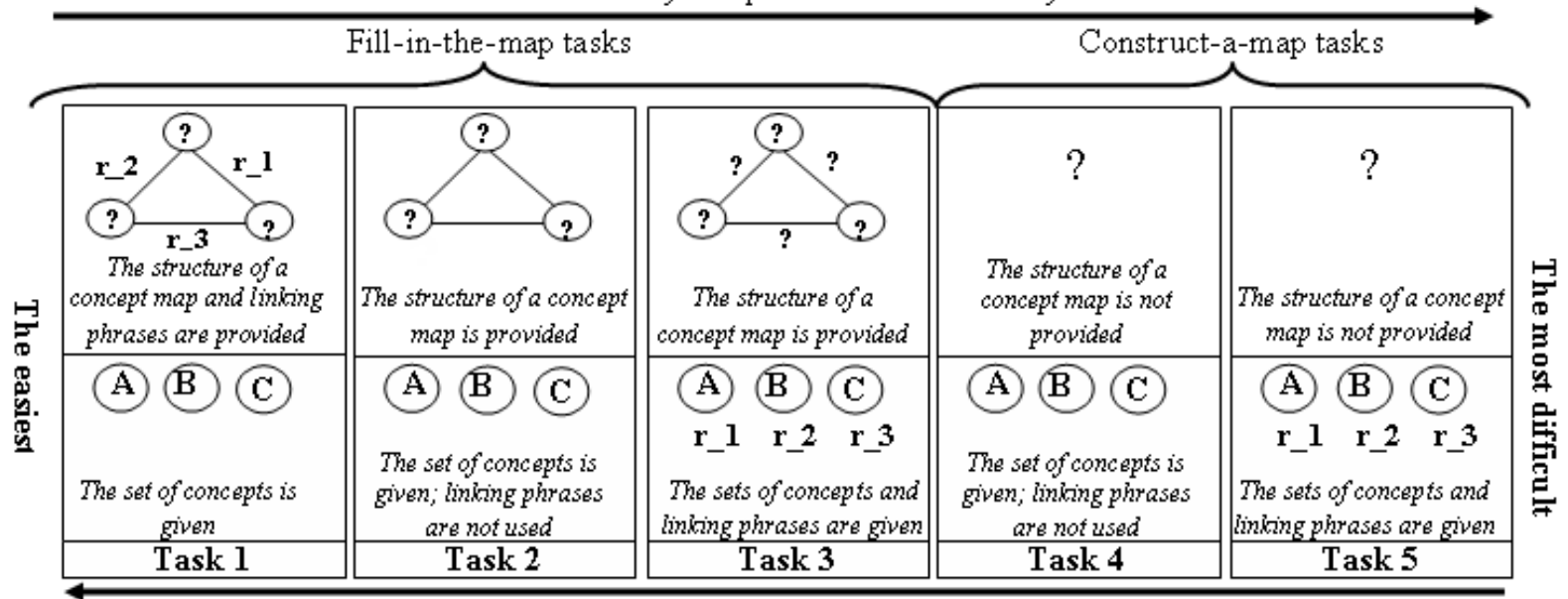

Reduction of difficulty: on request

Figure 1: Tasks offered in the concept map based knowledge assessment system

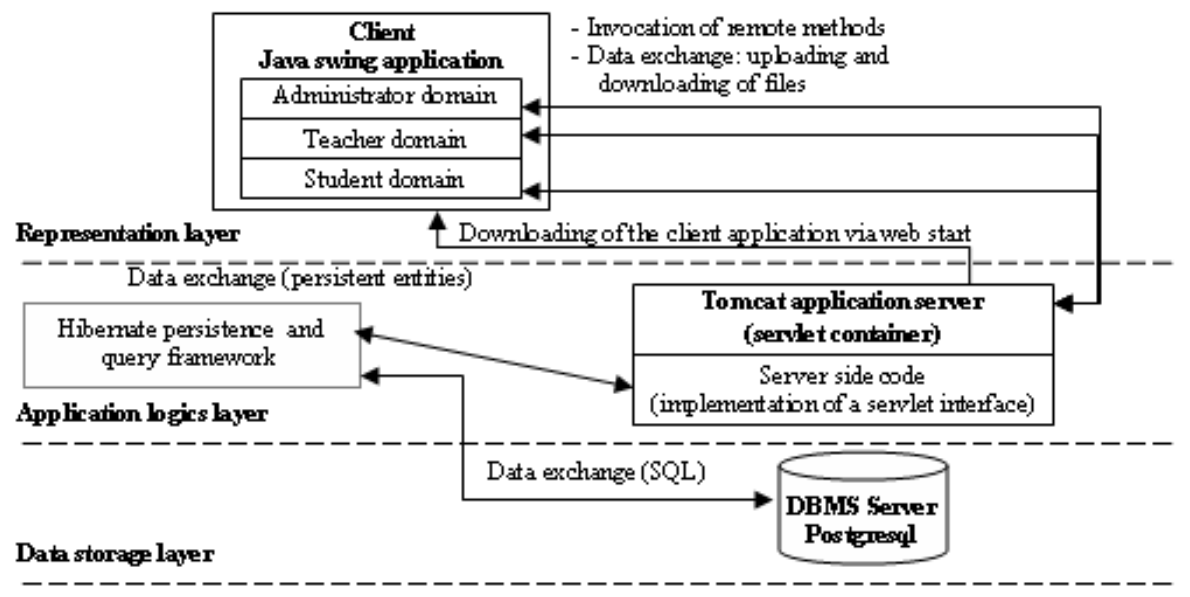

Figure 2: The three-tier architecture of the system

\section{Related works}

There are a lot of research related to scoring systems of concept maps. In [14] three main approaches are highlighted: evaluation of components of a concept map, comparison with the expert concept map, or combination of both previously mentioned kinds. Novak and Gowin [11] have offered a scheme in which different number of points are assigned to such components of a concept map as propositions, levels of hierarchy, cross-links, specific examples of concepts. In [13] the previously described set of components is extended by number of branchings in the concept map.

For the comparison of the learner's concept map with the expert map Goldsmith [8] has offered "the closeness index" indicating the degree of similarity between the expert and the learner's concept map. In turn, Herl and colleagues [9] use a matching algorithm that includes several expert maps evaluating each learner's concept map. In their work two evaluation indicators are calculated: (a) stringent semantic content score on the basis of the exact relationships matches between learner's and expert's concept 
maps, and b) categorized semantic content score, when learner's defined relationship matches some set of possible relationships in the expert concept map. In [10] concept maps are scored by comparing each learner's concept map with two expert maps. The learner receives half a point for each relationship that matches with an expert relationship and a full point, if the relationship matches with both experts' relationships. Learners also receive additional points for relationships that are more valued by experts ("critical relationships") and relationships that are less like what experts might include.

Both the evaluation of components of concept maps and the comparison with the expert concept map are combined in [12], where three different approaches to the scoring of concept maps are used: (a) a total score, defined as a number of valid learner's relationships, (b) a congruence score, defined as a proportion of valid learner's relationships to all relationships in the expert map, (c) a salience score, defined as a proportion of valid learner's relationships to all relationships in the learner's concept map.

Regardless of the diversity of schemes for scoring of concept maps, it is necessary to note that basically they are developed for the evaluation of tasks, in which learners must create their own concept maps. Thus, a question about the evaluation of fill-in-the-map tasks remains open. Moreover, the greater part of the offered schemes are not considered in the context of computer-assisted assessment systems, thus, it is very difficult to evaluate, whether they are feasible and useful in the concept map based knowledge assessment system. These factors motivated the authors of the paper to develop an algorithm suitable for the evaluation of both fill-in-the-map tasks and construct-a-map tasks in the concept map based knowledge assessment system.

\section{Evaluation algorithm}

The developed algorithm is sensitive to the arrangement and coherence of concepts in the learners' concept maps. It is based on the assumption that the learner's understanding of the presence of a relationship between concepts has the primary value, while other aspects such as the type of the relationship, the linking phrase, the direction of the arc and the places of concepts are secondary things. The algorithm is capable of recognizing different patterns of the learner's solution. Two kinds of relationships are used in concept maps: 1) important relationships which show that relationships between the corresponding concepts are considered as important knowledge in the learning course, and 2) less important relationships that specify desirable knowledge. For each correctly provided important relationship the learner receives 5 points, but for each less important relationship only 2 points are assigned.

In the first system's prototype developed in 2005 only one fill-in-the-map task was offered to learners. Thus, all learners received the same structure of a concept map and a list of concepts. Learners must insert provided concepts in correct nodes of the concept map structure. Arcs were undirected and did not have semantics. Taking into account that the value of a completely correct relationship is $100 \%$, the following contributions of its constituent parts were defined: the presence of the relationship in the learner's concept map - 50\% (a fact that the learner understands the presence of the relationship between concepts has the primary value), the correct type of the relationship - 30\% (the learner should be able to distinguish, what is important and what is less important in the learning course), both concepts related by the relationship are placed in the correct places - 20\% (this factor has the greatest subjectivity).

Thus, the patterns of the learner's solution which the algorithm was capable of recognizing are the following $[15,16]$ :

- Pattern 1. The learner has interrelated concepts in the same way as they are related in the teacher's concept map. In this case the learner receives the maximum score regarding the type of the relationship. Figure 3.b. shows that the concepts A and E in the learner's concept map are interrelated in the same way as they are interrelated in the teacher's concept map (Figure 3.a).

- Pattern 2. The learner has defined a relationship that does not exist in the concept map of the teacher. In this case he/she does not receive any points. Figure 3.c demonstrates that the learner 

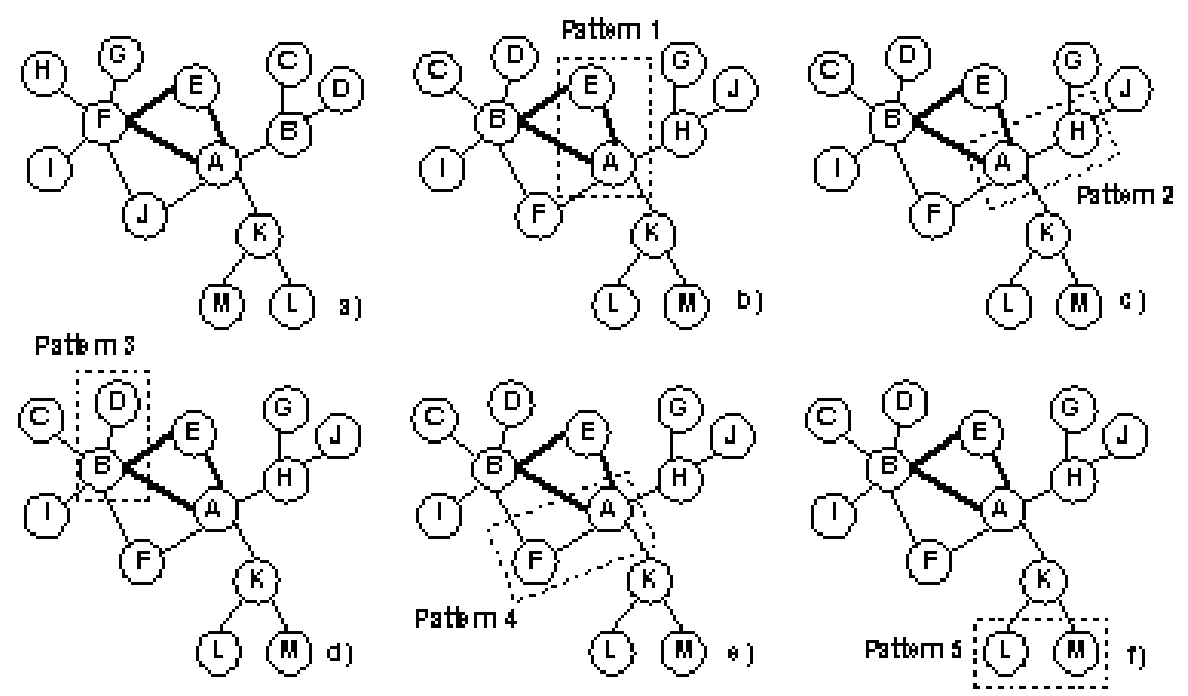

Figure 3: Patterns of the learner's solution that the first system's prototype was able to recognize: a) the teacher's concept map; b)-f) the patterns in the learner created concept map

has made a relationship between the concepts $\mathrm{A}$ and $\mathrm{H}$ that are not interrelated in the teacher's concept map (Figure 3.a).

- Pattern 3. The learner's defined relationship exists in the teacher's map, the type of the relationship is correct, but at least one of the concepts is placed in an incorrect place. The learner receives $80 \%$ of the maximum score for the correct relationship of this type. Figure 3.d shows that the learner has interrelated the concepts B and D. A similar relationship exists in the teacher's concept map (Figure 3.a). However, both concepts are located in incorrect places, although the type of the relationship is correct.

- Pattern 4. The learner's defined relationship exists in the teacher's map, the type of the relationship is wrong, and at least one of the concepts is placed in an incorrect place. The learner receives $50 \%$ of the maximum score for the correct relationship of this type. This pattern is displayed in Figure 3.e. Comparing the learner's defined relationship between the concepts $\mathrm{A}$ and $\mathrm{F}$ with the same teacher's relationship (Figure 3.a) it is possible to notice that the concept $F$ is located in the incorrect place, as well as the type of the relationship is a less important relationship instead of an important relationship.

- Pattern 5. A concept is placed in a wrong place, but its place is not important. The learner receives the maximum score for a corresponding relationship. Figure 3.f demonstrates that the learner has changed places of the concepts $\mathrm{M}$ and $\mathrm{L}$.

New tasks - 3 fill-in-the-map and 2 construct-a-map tasks (Figure 1)- were introduced in the second system's prototype developed in 2006. Moreover, linking phrases were added to concept maps causing modification of points received for relationships and extension of the set of patterns recognized by the system. Assuming that a value of the fully correct relationship is $100 \%$, the following contributions of its constituent parts were defined: the presence of the relationship in the learner's concept map - 40\%, a correct linking phrase provided for the relationship - 30\% (semantics of relationships are important knowledge units), a correct type of the relationship - 20\%, both concepts related by the relationship are placed in the correct places - $10 \%$.

Therefore, the extended set of patterns of the learner's solution was the following [6]: 
- Pattern 1. The learner has defined a completely correct relationship. In this case the learner receives the maximum score regarding the type of the relationship. Figure 4.b demonstrates that the concepts $\mathrm{A}$ and $\mathrm{E}$ in the learner's concept map are interrelated in the same way as they are interrelated in the teacher's concept map (Figure 4.a).

- Pattern 2. The learner has defined a relationship that does not exist in the concept map of the teacher and he/she does not receive any points. Figure 4.c shows that the learner has related the concepts $\mathrm{A}$ and $\mathrm{H}$ which are not related in the teacher's map (Figure 4.a).

- Pattern 3. The learner's defined relationship exists in the teacher's map, both the type of the relationship and the linking phrase are correct, but at least one of the concepts is located in an incorrect place. The learner receives $90 \%$ of the maximum score for that relationship. This pattern is displayed in Figure 4.d. The learner has defined the relationship between the concepts B and D by providing the correct type of the relationship and the linking phrase. However, both concepts are located in different places as compared to the teacher's concept map (Figure 4.a).

- Pattern 4. The learner's defined relationship exists in the teacher's map, but the type of the relationship is incorrect. The learner receives $80 \%$ of the maximum score for the correct relationship. This pattern is valid only for construct-a-map tasks (Tasks 4 and 5 in Figure 1) where places of concepts are not important. Assuming that Figure 4.e displays the learner's created concept map, one can see that the learner has interrelated the concepts $\mathrm{B}$ and $\mathrm{C}$ by defining the correct linking phrase, but providing the important relationship instead of a less important one as it is in the teacher's map (Figure 4.a).

- Pattern 5. The learner's defined relationship exists in the teacher's map, but the linking phrase is incorrect. The learner receives $70 \%$ of the maximum score for the correct relationship. Figure 4.f shows that the learner has located the concepts $\mathrm{A}$ and $\mathrm{K}$ in the same places as they are located in the teacher's concept map (Figure 4.a), but the linking phrase differs.

- Pattern 6. The learner's defined relationship exists in the teacher's map, the type of the relationship is incorrect, and at least one of concepts is placed in the incorrect place. The learner receives $70 \%$ of the maximum score. Figure 4.g shows that the learner has related the concepts A and F using the less important relationship instead of the important relationship (Figure 4.a) and has located the concept $\mathrm{F}$ in other place.

- Pattern 7. The learner's defined relationship exists in the teacher's map, the linking phrase is incorrect, and at least one of concepts is located in the incorrect place. The learner receives $60 \%$ of the maximum score. This pattern is displayed in Figure 4.h, where one can see that the learner has defined the relationship between the concepts $\mathrm{G}$ and $\mathrm{F}$, but has pointed out the linking phrase that differs from the linking phrase in the teacher's concept map (Figure 4.a), as well as has located both concepts incorrectly.

- Pattern 8. The learner's defined relationship exists in the teacher's map, but both the type of the relationship and the linking phrase are incorrect. The learner receives $50 \%$ of the maximum score for the correct relationship. This pattern is valid only for construct-a-map tasks (Tasks 4 and 5 in Figure 1), where places of concepts are not important. Assuming that Figure 4.i displays the learner's created concept map, one can see that the learner has interrelated the concepts $\mathrm{O}$ and $\mathrm{B}$ that are also interrelated in the teacher's concept map (Figure 4.a). The learner has provided an incorrect type of the relationship (an important relationship instead of a less important relationship) and an incorrect linking phrase. 



Figure 4: Patterns of the learner's solution that the second system's prototype was able to recognize: a) the teacher's concept map; b)-j) the patterns in the learner created concept map (numbers on links display different relationships and represent linking phrases) 
- Pattern 9. The learner's defined relationship exists in the teacher's map, both the type of the relationship and the linking phrase are incorrect, in addition at least one of the concepts is placed in the incorrect place. The learner receives $40 \%$ of the maximum score for that relationship. This pattern is shown in Figure 4.j. By comparing the learner's defined relationship between the concepts $\mathrm{J}$ and $\mathrm{N}$ with the same relationship in the teacher's concept map (Figure 4.a), one can see that both concepts are located in incorrect places, and the type of the relationship and the linking phrase are incorrect.

In the third prototype implemented in 2007 directed arcs were introduced causing the following modifications of points received for relationships: the presence of the relationship in the learner's concept map - 40\%, a correct linking phrase provided for the relationship - 30\%, a correct direction of the arc corresponding to the relationship - 15\%, a correct type of the relationship - 10\%, both concepts related with the relationship are placed in the correct places - 10\%. Totally 36 patterns were acquired for all tasks and they are summarized in Figure 5.

No modifications of points have been made in the fourth system's prototype. Thus, the evaluation algorithm is based on the set of patterns specified in Figure 5. However, improvement of the algorithm is continued by studying possibility to reveal extra relationships in learners' concept maps [17]. Figure 6 displays a situation when some relationships are "hidden": there are only 3 relationships in the teacher's concept map (Figure 6.a), but 2 more relationships can be derived (Figure 6.b). These derived relationships are correct too and could appear in learners' concept maps, so it is necessary to define a mechanism according to which the system could detect extra relationships and, thus, make assessment more flexible and automated.

With aim to determine extra relationships 6 types of relationships are considered [17]:is a - a relationship between concepts meaning that one of the concepts is a sub-class of other, part of - a relationship between concepts meaning that one of the concepts is a part of other, attribute - a relationship between a concept and its attribute, example - a relationship between a general concept and a particular example of it, value - a relationship between an attribute and its value, kind of - a relationship between levels of hierarchy.

Figure 7 shows the structure of a pattern further explained in Figure 8. The pattern has two main relationships (Relation 1 and Relation 2) that have types mentioned previously. In some cases combination between relationships is not allowed. In other cases an extra relationship (Relation 3) can be formed. Column "Combination allowed" identifies either combination between Relation 1 and Relation 2 is allowed or not. The entry "Cannot be specified" in the column "Relation 3" indicates that there can be situations when an extra relationship can be added, but not always. In turn, the entry "No extra relationship" in the same column points out that no additional relationship of considered 6 types can be added.

Additional relationships that can be derived from more than three concepts and two relationships between them can be revealed as well. In such case the algorithm must iteratively go through the concept map searching for patterns and adding extra relationships whenever it is possible. The algorithm stops when no new relationship has been added during the last iteration.

\section{Conclusions}

The use of concept maps for the evaluation of learners' knowledge structures demands an appropriate mechanism for the comparison of learners' concept map with the teacher's one. The mechanism should consider that people construct knowledge in different ways and there can be differences between concept maps that are not indicators of incorrect knowledge. The paper presents the algorithm capable of recognizing several patterns of the learner's solution on the basis of such criteria as location of concepts, types of relationships, direction of arcs and correctness of linking phrases allowing the learner to receive 


\begin{tabular}{|c|c|c|c|c|c|c|}
\hline $\begin{array}{l}\text { The presence of } \\
\text { the relationshi }\end{array}$ & \begin{tabular}{|l|} 
Location of ooncepts \\
in the comrect plaoes
\end{tabular} & $\begin{array}{l}\text { Type of the } \\
\text { relationship }\end{array}$ & $\begin{array}{c}\text { Direction of } \\
\text { the arc }\end{array}$ & Linking phuase & Points & Conments \\
\hline \multirow[t]{17}{*}{ Exits } & $\begin{array}{l}\text { Both places are } \\
\text { correct or plaoes are } \\
\text { not irmortart (Tasks } \\
4 \text { and } 5 \text { in Figure 1) }\end{array}$ & Conect & Conect & $\begin{array}{l}\text { Conect or not used } \\
(\text { Tasks } 2 \text { and } 4 \text { in } \\
\text { Figure 1) }\end{array}$ & Maxirnm soore & $\begin{array}{l}\text { A correletely comect } \\
\text { relationshi }\end{array}$ \\
\hline & $\begin{array}{l}\text { Both oonoepts are } \\
\text { located in conect } \\
\text { places }\end{array}$ & Conect & Conect & Inoorrect & $0.7 *$ Maxirnm soore & $\begin{array}{l}\text { Applicable to Task3 in } \\
\text { Figure } 1\end{array}$ \\
\hline & \multirow{8}{*}{$\begin{array}{l}\text { At least one of } \\
\text { concepts is bcated in } \\
\text { the moorect place }\end{array}$} & Conect & Conect & $\begin{array}{l}\text { Conect or not used } \\
(\text { Task } 2 \text { in Figure 1) }\end{array}$ & $095 *$ Maxirum score & $\begin{array}{l}\text { Applicable to Taks 1,2 } \\
\text { and } 3 \text { in Figure } 1\end{array}$ \\
\hline & & Conect & Conect & İnoorrect & $065 *$ Maxirum score & $\begin{array}{l}\text { Applicable to Taks } 1 \text { and } \\
3 \text { in Figure } 1\end{array}$ \\
\hline & & Conect & Inoorect & $\begin{array}{l}\text { Conect or not used } \\
\text { (Task } 2 \text { in Figure 1) }\end{array}$ & $08 *$ Maxirnm soore & $\begin{array}{l}\text { Applicable to Taks 1,2 } \\
\text { and } 3 \text { in Figure } 1\end{array}$ \\
\hline & & Inoorrect & Conect & $\begin{array}{l}\text { Conect or not used } \\
\text { (Task } 2 \text { in Figure 1) }\end{array}$ & $085 *$ Maxirnum score & $\begin{array}{l}\text { Applicable to Taks 1,2 } \\
\text { and } 3 \text { in Figure } 1\end{array}$ \\
\hline & & Inoorrect & Conect & Inoorect & 055* Maxiroum score & $\begin{array}{l}\text { Applicable to Taks } 1 \text { and } \\
3 \text { in Figure } 1\end{array}$ \\
\hline & & Conect & Inoorrect & Inoorrect & $05^{*}$ Maxirnm soore & $\begin{array}{l}\text { Applicable to Taks } 1 \text { and } \\
3 \text { in Figure } 1\end{array}$ \\
\hline & & Inoorrect & Inoorrect & $\begin{array}{l}\text { Conect or not used } \\
\text { (Task } 2 \text { in Figure 1) }\end{array}$ & $0.7 *$ Maxirnm soore & $\begin{array}{l}\text { Applicable to Taks 1,2 } \\
\text { and } 3 \text { in Figure } 1\end{array}$ \\
\hline & & Inoorrect & Inoorrect & Inoorrect & $0.4 *$ Maxirnm soore & $\begin{array}{l}\text { Applicable to Taks } 1 \text { and } \\
3 \mathrm{in} \text { Figure } 1\end{array}$ \\
\hline & \multirow[t]{7}{*}{$\begin{array}{l}\text { Places of conoepts } \\
\text { are not impontant }\end{array}$} & Conect & Inoorrect & $\begin{array}{l}\text { Conect or not used } \\
\text { (Task } 4 \text { in Figure 1) }\end{array}$ & $085 *$ Maxirnum score & $\begin{array}{l}\text { Applicable to Taks } 4 \text { and } \\
5 \text { in Figure } 1\end{array}$ \\
\hline & & Inoorect & Conect & $\begin{array}{l}\text { Conect or not used } \\
\text { (Task } 4 \text { in Figure 1) }\end{array}$ & 0g* Maxirnm soore & $\begin{array}{l}\text { Applicable to Tasks } 4 \text { and } \\
5 \text { in Figure } 1\end{array}$ \\
\hline & & Inoorect & Inoorrect & $\begin{array}{l}\text { Conect or not used } \\
\text { (Task } 4 \text { in Figure 1) }\end{array}$ & $0.75 *$ Maxirnum score & $\begin{array}{l}\text { Applicable to Taks } 4 \text { and } \\
5 \text { in Figure } 1\end{array}$ \\
\hline & & Conect & Conect & Inoorrect & $0.7 *$ Maxirnm soore & $\begin{array}{l}\text { Applicable to Task S in } \\
\text { Figure } 1\end{array}$ \\
\hline & & Conect & Inoorrect & Inoorrect & $055 *$ Maxirum score & $\begin{array}{l}\text { Applicable to Tak S in } \\
\text { Figure } 1\end{array}$ \\
\hline & & Inoorrect & Conect & Inoorrect & $06^{*}$ Maxirnm soore & $\begin{array}{l}\text { Applicable to Tak } 5 \text { in } \\
\text { Figure } 1\end{array}$ \\
\hline & & Inoorrect & Inoorrect & Inoorrect & $0.45 *$ Maxirnum score & $\begin{array}{l}\text { Applicable to Tak S in } \\
\text { Figure } 1\end{array}$ \\
\hline Does not exit & & & & & 0 points & $\begin{array}{l}\text { A conqletely incorrect } \\
\text { relationshị }\end{array}$ \\
\hline
\end{tabular}

Figure 5: The extended set of patterns of the learner's solution in the third system's prototype
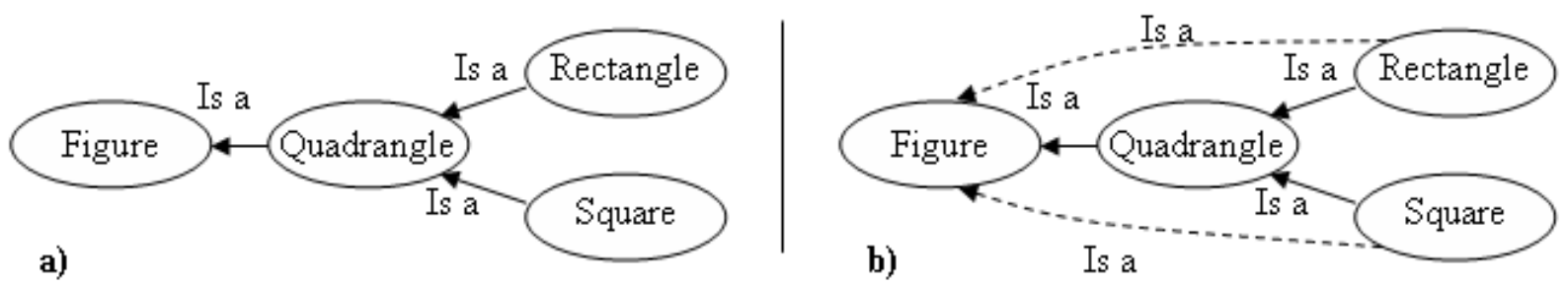

Figure 6: Hidden relationships (adopted from [17])

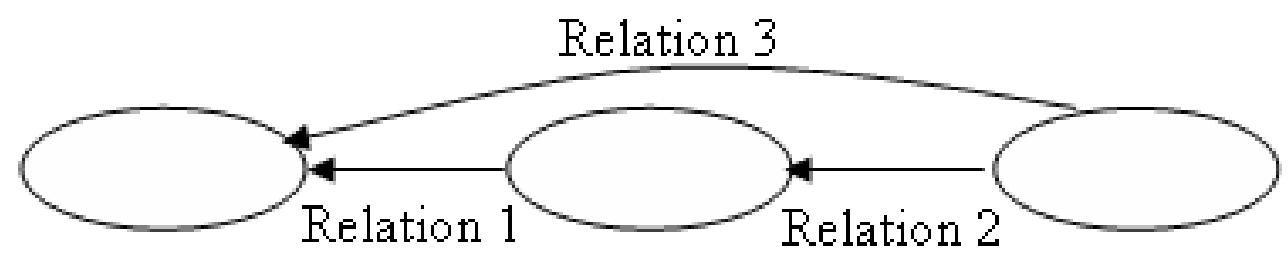

Figure 7: Structure of the pattern (adopted from [17]) 
some points in case if his/her relationships match teacher's ones only partly. Moreover, detection of extra relationships that can appear in learners' concept maps makes assessment more automated.

\begin{tabular}{|c|c|c|c|}
\hline Relation 1 & Relation 2 & Combination allowed & Relation 3 \\
\hline Is a & Is a & Yes & Is a \\
\hline Is a & Part of & Yes & Part of \\
\hline Is a & Attribute & Yes & Cannot be specified \\
\hline Is a & Example & Yes & Is a \\
\hline Is a & Value & No &  \\
\hline Is a & Kind of & Yes & Is a \\
\hline Part of & Is a & Yes & Part of \\
\hline Part of & Part of & Yes & Part of \\
\hline Part of & Attribute & Yes & Carrot be specified \\
\hline Part of & Example & Yes & Part of \\
\hline Part of & Value & No & - \\
\hline Part of & Kind of & Yes & Part of \\
\hline Attribute & Value & Yes & No extra relationship \\
\hline Attribute & Any other except "Value" and linguistic & No & - \\
\hline Exarmple & Is a & Yes & No extra relationship \\
\hline Example & Part of & Yes & No extra relationship \\
\hline Example & Attribute & Yes & Cannot be specified \\
\hline Example & Example & No & - \\
\hline Example & Value & No & - \\
\hline Example & Kind of & Yes & No extra relationship \\
\hline Value & Any other except linguistic & No & - \\
\hline Kind of & Part of & Yes & Part of \\
\hline Kind of & Is a & Yes & Is a \\
\hline Kind of & Kind of & Yes & Is a \\
\hline Kind of & Example & Yes & Example \\
\hline Kind of & Attribute & Yes & Cannot be specified \\
\hline Kind of & Value & No & - \\
\hline
\end{tabular}

Figure 8: Patterns containing three concepts and two relationships (adopted from [17])

\section{Bibliography}

[1] A.Styliadis, I.Karamitsos, D.Zachariou,Personalized e-Learning Implementation-the GIS Case, International Journal of Computers, Communications \& Control, Vol.1, No.1, pp.59-67, 2006.

[2] G. Moise, A Software System for Online Learning Applied in the Field of Computer Science, International Journal of Computers, Communications \& Control, Vol.2, No.1, pp.84-93, 2007.

[3] J. Grundspenkis, A. Anohina, Evolution of the Concept Map Based Adaptive Knowledge Assessment System: Implementation and Evaluation Results, Scientific Proceedings of Riga Technical University, RTU Publishing, Riga, 2008 (submitted).

[4] M. Vilkelis, A. Anohina, R. Lukashenko, Architecture and Working Principles of the Concept Map Based Knowledge Assessment System, Proceedings of the 3rd International Conference on Virtual Learning, October 31 - November 2, Constanta, Romania, pp. 81-90, 2008.

[5] A. J. Cañas, A Summary of Literature Pertaining to the Use of Concept Mapping Techniques and Technologies for Education and Performance Support, Technical report, 2003.

[6] A. Anohina, D. Pozdnakovs, J. Grundspenkis, Changing the Degree of Task Difficulty in Concept Map Based Assessment System, Proceedings of the IADIS International Conference "e-Learning 2007", July 6-8, Lisbon, Portugal, pp. 443-450, 2007.

[7] R. Lukashenko, M. Vilkelis, A. Anohina, Deciding on the Architecture of the Concept Map Based Knowledge Assessment System,Proceedings of the International Conference on Computer Systems and Technologies, June 12-13, Gabrovo, Bulgaria, pp. V.3-1 - V.3-6, 2008. 
[8] T. E. Goldsmith, P. J. Johnson, W. H. Acton, Assessing Structural Knowledge, Journal of Educational Psychology, Vol.83, No.1, pp. 88-96, 1991.

[9] H. Herl, E. Baker, D. Niemi, Construct Validation of an Approach to Modelling Cognitive Structure of U.S. History Knowledge, Journal of Educational Research, No. 89, pp. 206-219, 1996.

[10] D. C. D. Klein, G. K. W. K. Chung, E. Osmundson, et al., Examining the Validity of Knowledge Mapping as a Measure of Elementary Students' Scientific Understanding, CSE techical report No.557, 2002.

[11] J. D. Novak, D. B. Gowin, Learning How to Learn, London, 1984.

[12] M. A. Ruiz-Primo, R. J. Shavelson, S. E. Schultz, On the Validity of Concept Map-Based Assessment Interpretations: an Experiment Testing the Assumption of Hierarchical Concept Maps in Science, CSE Technical Report 455, 1997.

[13] J. D. Wallace, J. J. Mintzes, The Concept Map as a Research Tool: Exploring Conceptual Change in Biology, Journal of Research in Science Teaching, Vol. 27, pp. 1033-1052, 1990.

[14] M. A. Ruiz-Primo, R. J. Schavelson, Problems and Issues in the Use of Concept Maps in Science Assessment, Journal of Research in Science Teaching, No.6, pp. 569-600, 1996.

[15] A. Anohina, J. Grundspenkis, Prototype of Multiagent Knowledge Assessment System for Support of Process Oriented Learning, Proceedings of the 7th International Baltic Conference on Databases and Information Systems, July 3-6, Vilnius, Lithuania, pp. 211-219, 2006.

[16] A. Anohina, V. Graudina, J. Grundspenkis, Using Concept Maps in Adaptive Knowledge Assessment, Advances in Information Systems Development "New Methods and Practice for the Networked Society", Springer, pp. 469-480, 2006.

[17] J. Grundspenkis, M. Strautmane, Usage of Graph Patterns for Knowledge Assessment Based on Concept Maps. Scientific Proceedings of Riga Technical University, RTU Publishing, Riga, 2008 (submitted).

Alla Anohina is a lecturer at the Department of Systems Theory and Design of Riga Technical University in Latvia. She obtained her doctoral degree in Computer Systems from Riga Technical University in 2007. Her main research fields are intelligent tutoring systems, computer-assisted assessment systems and artificial intelligence. She has seven years' experience of teaching in the field of computer science both in Riga Technical University, and in other educational institutions of Latvia. She has participated in several research projects related to the development of of educational software.

Marks Vilkelis is currently developing the master thesis "The knowledge assessment system as a client-server java application" at the Institute of Information Technology of Riga Technical University. In 2005 he obtained the bachelor degree from the mentioned institution. His scientific interests cover Java open source technologies and applications of artificial intelligence. He has experience of working as a programmer in some research projects. His professional activities are related to the programming of complex business applications in the international software development company.

Romans Lukasenko is a PhD student of Computer Systems at the Riga Technical University in Latvia. He obtained the master degree in Computer Systems from the mentioned institution in 2006. His main research fields are intelligent tutoring systems, computer-assisted assessment systems and student modelling. His thesis is related to the implementation of a student model in the knowledge assessment system. Romans Lukashenko works also as a researcher at the Department of Systems Theory and Design of Riga Technical University. He has participated in several research projects related to the development of educational software. 